\title{
Estimating normal effective stress degradation in sand under undrained simple shear condition
}

\author{
Ze-Xiang Wu ${ }^{a, b, c}$, Christophe Dano ${ }^{d}$, Pierre-Yves Hicher ${ }^{c}$ and Zhen-Yu Yin ${ }^{b}$ \\ ${ }^{\mathrm{a}}$ College of Architecture and Civil Engineering, Wenzhou University, Wenzhou, China; ${ }^{\mathrm{b}}$ Department of Civil \\ and Environmental Engineering, The Hong Kong Polytechnic University, Hong Kong, China; ${ }^{\circ}$ Research \\ Institute of Civil Engineering and Mechanics (GeM), UMR CNRS 6183, Ecole Centrale de Nantes, Nantes,

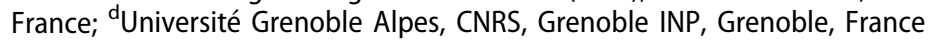

\begin{abstract}
The degradation of the effective normal stress in soil surrounding the pile caused by undrained cyclic loading affects the shaft capacity of the pile and can lead to structural instability. In order to investigate this phenomenon, a series of constant volume monotonic and cyclic simple shear tests on Fontainebleau sand has been conducted. Based on the experimental results, the shear stress at phase transformation state is first determined for different initial void ratios and initial normal effective stresses. Then, the number of cycles to liquefaction is estimated as a function of both the cyclic and the average shear stresses normalised by the shear stress at phase transformation. An empirical equation to evaluate the normal stress degradation is formulated and the procedure of parameter identification is presented. The performance of the suggested formulation has been analysed, based on simple shear test results on Fraser River sand and Quiou sand, and triaxial tests on Karlsruhe sand, and it has been validated by a series of additional tests on Fontainebleau sand. All the results indicate that the proposed formulation is able to estimate with good accuracy the effective normal stress degradation in sand subjected to undrained cyclic shearing.
\end{abstract}

\section{Introduction}

Pile foundations are generally subjected to lateral and axial, monotonic and cyclic loads, as for example is the case for wind turbines. Because the severity of the loads can induce a degradation of the shaft capacity (Andersen, 2009; Gavin, Igoe, \& Doherty, 2011), in particular of the axial cyclic components, it needs to be more deeply investigated. Indeed, the initial horizontal effective stress at the interface between the soil and the pile, governing the level of the local shear resistance and thus the global shaft capacity, could be gradually reduced due to the generation of excess pore pressure during cyclic loading. Therefore, it is highly valuable to develop analytical methods which address the changes of the soil properties so that the evolution of the shaft capacity of piles under cyclic loading can be more easily interpreted.

Field and laboratory model pile tests have been performed to understand the evolution of the shaft capacity during pile installation and service conditions inducing cyclic axial loading (Aghakouchak, Sim, \& Jardine, 2015; Jardine, Chow, Overy, \& Standing, 2005; Jardine \& Standing, 
2012; Jardine, Standing, Health and Safety Executive, London, 2000; Pra-Ai, 2013; Tsuha et al., 2012; Yang, Jardine, Zhu, Foray, \& Tsuha, 2010). Full-scale pile tests subjected to axial cyclic loading performed by Jardine et al. (2000) demonstrated that high-level cyclic loading can be highly detrimental to shaft capacity. In laboratory conditions, tests using the mini-ICP (Imperial College Pile) model pile installed in a pressurised calibration chamber (Tsuha et al., 2012; Yang et al., 2010) have also provided key information for improving the modelling of pile-soil interaction and the design rules. Based on their recent works on the degradation of shaft capacity in model pile tests, Jardine et al. (2005) and Aghakouchak et al. (2015) have suggested an empirical 'ABC' formulation involving the shaft cyclic shear stress $\left(\tau_{\text {cyc }}\right)$ normalised by the maximum static shear stress $\tau_{\text {max,static }}$ and the number of cycles $(N)$ :

$$
\frac{\Delta \sigma_{n}^{\prime}}{\sigma_{n 0}^{\prime}}=A \cdot\left[B+\frac{\tau_{c y c}}{\tau_{\max , \text { static }}}\right]^{C} \cdot \log _{10}(N)
$$

where $\sigma_{n 0}^{\prime}$ is the initial effective normal stress to the shaft and $\Delta \sigma_{n}^{\prime}$ the variation (degradation) of the normal effective stress. $A, B$, and $C$ are three constant empirical values which can be identified through back-analysis of pile tests or through calibration from laboratory experiments. However, the influence of the mean shear stress $\tau_{\text {ave }}$ has not been introduced in the 'ABC' model (Tsuha et al., 2012).

Similarly, in order to investigate the soil response under cyclic loading, various cyclic tests such as triaxial tests, simple or direct shear tests, torsional shear tests (Aghakouchak et al., 2015; Andersen, 2009; Hyodo, Murata, Yasufuku, \& Fujii, 1991; Jin, Yin, Zhang, \& Huang, 2015; Qian, Du, \& Yin, 2018; Qian, Wang, Yin, \& Huang, 2016; Vaid, Stedman, \& Sivathayalan, 2001; Yin, Chang, \& Hicher, 2010; Yin, Wu, \& Hicher, 2018; Yin, Xu, \& Chang, 2013; Yoshimine, Ishihara, \& Vargas, 1998; Yoshimine, Robertson, \& Wride, 1999), have also been conducted, usually by assuming uniform load-controlled cycles on the specimen in undrained conditions. Based on these soil element tests, various empirical equations have been proposed for predicting the soil response concerning the generation of pore pressure or the degradation of the effective normal stress. Based on cyclic triaxial tests, Seed and Idriss (1971) have defined a uniformed ' $S$ ' shape for the generation of excess pore pressure which can be formulated by an arcsine function depending on a normalised number of cycles to liquefaction (Mitchell \& Dubin, 1986; Mohtar, Bobet, Drnevich, Johnston, \& Santagata, 2014; Polito, Green, \& Lee, 2008; Porcino, Marcianò, \& Granata, 2015; Wang, Guo, Cai, $\mathrm{Xu}, \& \mathrm{Gu}, 2013)$. Ishibashi, Sherif, and Tsuchiya (1977) have developed a model of incremental pore pressure depending on the shear stress amplitude and the number of cycles (Georgiannou \& Tsomokos, 2008; Ishibashi, Sherif, \& Cheng, 1982; Konstadinou \& Georgiannou, 2014; Krishnaswamy \& Thomas Isaac, 1995; Sherif, Ishibashi, \& Tsuchiya, 1978; Wang, Cai, \& Yang, 2013). Nemat-Nasser and Shokooh (1979) have introduced an 'energy-based' method in which the generation of excess pore pressure is related to the amount of dissipated energy (shear work) during cyclic loading (Dief \& Figueroa, 2007; Green, Mitchell, \& Polito, 2000; Law, Cao, \& He, 1990; Towhata \& Ishihara, 1985). Note that the influence of the initial average shear stress, which is however known as a key factor to enhance the cyclic resistance of sand (Gu et al., 2016; Vaid \& Chern, 1983; Vaid et al., 2001; Yang \& Sze, 2011; Yang \& Pan, 2017), has not been considered in these predictive models. Hence, a more efficient approach for describing more precisely the degradation of the effective normal stresses acting on a pile shaft must include the investigation of the influence of the initial average shear stress.

Until now, only laboratory experiments have been considered to quantify the degradation of the effective normal stress due to shearing. Most experimental studies have limited this scope on results from triaxial tests. In spite of their shortcomings (Andersen, 2009), simple shear tests have been preferred to triaxial tests since the interface shearing is much better reproduced through this type of testing, even if direct shear testing could also be considered (Pra-Ai, 2013; Pra-Ai \& Boulon, 2017; Wang, Liu, Wang, \& Cai, 2016). Similarly, even if it is now currently 


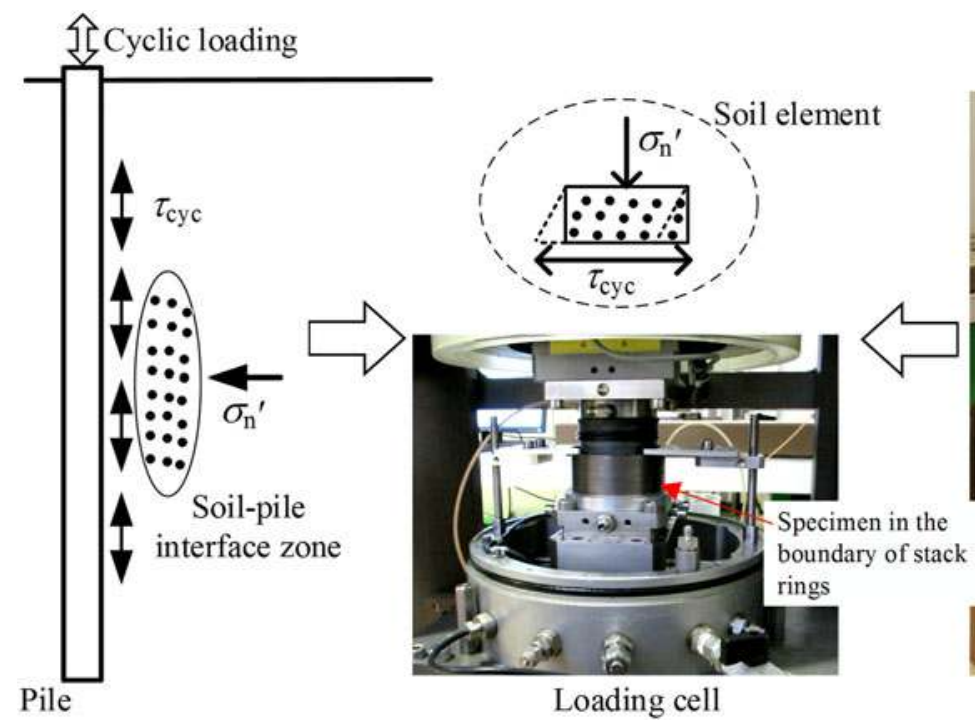

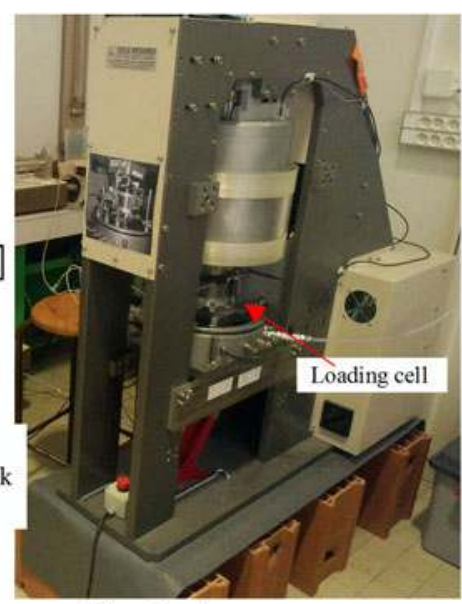

Simple shear apparatus

Figure 1. Analysis of soil element adjacent to pile based on simple shear apparatus.

accepted that the shearing of a soil-pile interface occurs at a relatively constant normal stiffness (Fakharian \& Evgin, 1997), a conservative approach would be to in perform constant volume simple shear tests, which maximises the degradation of the effective normal stress, as previously done in (Andersen, 2009; Dyvik, Berre, Lacasse, \& Raadim, 1987; Lambe \& Whitman, 1969) for instance. The stress state of a soil element around the pile foundation is shown in Figure 1. The soil element is subjected to cyclic loading with symmetrical loading $\left(\tau_{\text {ave }}=0\right)$ or non-symmetrical loading ( $\left.\tau_{\text {ave }} \not \equiv 0\right)$.

From the above literature review, the following points could be noted. First, in the laboratory, soil element tests would greatly simplify the testing operation and reduce significantly the financial cost compared to full size or even model pile tests for studying the soil response during cyclic loading. Second, the effect of the initial average shear stress is rarely investigated. Third, compared with triaxial tests, simple shear tests are acknowledged to provide more representative loading conditions for interface shearing.

This study, therefore, aims to provide a contribution to characterise the degradation of the effective normal stress based on undrained monotonic and cyclic simple shear tests on Fontainebleau sand and to develop a procedure for calibrating this degradation. Following these objectives, the first task was to determine by undrained monotonic simple shear tests the phase transformation line (PTL), since the position of the PTL governs the volumetric behaviour and, therefore, the pore pressure evolution. Then, the number of cycles to liquefaction was investigated based on the results of cyclic simple shear tests under different loading conditions. Furthermore, an empirical formulation expressing the degradation of the effective normal stress during cyclic loading was developed. Then, experimental data on Fraser River sand and carbonate sand from Quiou (France) obtained through simple shear tests on the one hand, and on Karlsruhe sand subjected to triaxial loading on the other hand, were selected from the literature review to verify the proposed calibration procedure. Finally, a series of additional tests were performed on Fontainebleau sand in order to verify the accuracy of the proposed empirical equation.

\section{Material and testing programme}

The tested material is the Fontainebleau sand NE34, a fine siliceous sand with sub-rounded grains (Figure 2(a)). Its main characteristics, summarised in Table 1, are a mean grain size of 




(a)
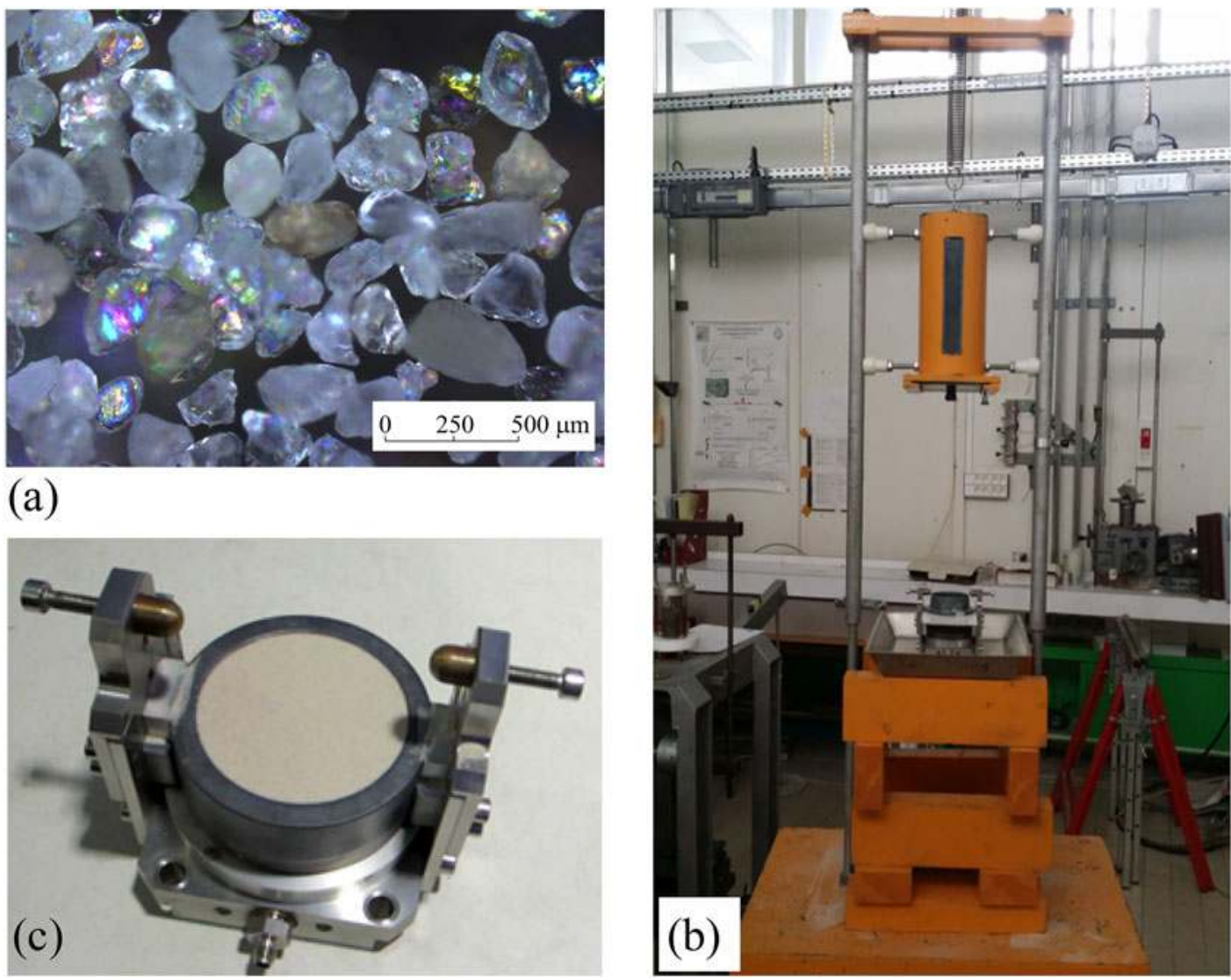

Figure 2. Details of specimens preparation: (a) particle shape of Fontainebleau sand, (b) air-pluviation technique, (c) sand specimen.

Table 1. Physical properties of standard Fontainebleau.

\begin{tabular}{lcccccc}
\hline Grain shape & $\mathrm{S}_{\mathrm{i}} \mathrm{O}_{2}(\%)$ & $D_{50}(\mathrm{~mm})$ & $C_{\mathrm{u}}\left(D_{60} / D_{10}\right)$ & $G_{\mathrm{s}}$ & $e_{\max }$ & $e_{\min }$ \\
\hline Sphericity & 99.70 & 0.21 & 1.53 & 2.65 & 0.882 & 0.510 \\
\hline
\end{tabular}

about $210 \mu \mathrm{m}$, a coefficient of uniformity of 1.53 , minimum and maximum void ratios of 0.510 and 0.882 , respectively, a specific weight of $26.00 \mathrm{kN} / \mathrm{m}^{3}$ (Andria-Ntoanina, Canou, \& Dupla, 2010). As a reference material in France for geotechnical applications, this sand has been used in many experimental studies. Its cyclic behavior has been relatively well documented at the scale of the representative elementary volume in laboratory tests as well as at the scale of soil-structure interactions (Dupla \& Canou, 1994; Gaudin, Schnaid, \& Garnier, 2005; Gu, Wang, Cai, \& Guo, 2014; Pra-ai \& Boulon, 2017; Yang et al., 2010), resulting in the establishment of the Poulos cyclic stability diagram (Poulos, 1988).

The simple shear device used in this study is a commercial apparatus whose design is close to the NGl simple shear apparatus (Bjerrum \& Landva, 1966). The servo-controlled system is capable of conducting stress or strain controlled loading paths in both horizontal and vertical directions (Figure 1). An air-pluviation technique was developed to prepare the specimens, as shown in Figure 2(b), in which the sand is deposited from a predetermined height into the specimen mold in order to obtain a predetermined relative density. For sands, the cylindrical reconstituted specimens, $70 \mathrm{~mm}$ in diameter and $25 \mathrm{~mm}$ in height (ratio of 0.36 to minimise the effects of friction on the lateral sides), were prepared by air-pluviation, which is considered to approximate the natural deposition process (Vaid \& Negussey, 1984). The specimens are confined in a soft 
Table 2. Summary of experiments on tested Fontainebleau sand.

\begin{tabular}{|c|c|c|c|c|c|c|c|c|c|c|c|}
\hline Test No. & \multicolumn{2}{|c|}{ Loading type } & $e_{0}$ & $D_{\mathrm{r} 0} \%$ & $\sigma_{\mathrm{n} 0}^{\prime}(\mathrm{kPa})$ & $\tau_{\mathrm{pt}}(\mathrm{kPa})$ & $\tau_{\text {ave }}(\mathrm{kPa})$ & $\tau_{\text {cyc }}(\mathrm{kPa})$ & $\tau_{\text {ave }} / \sigma_{n 0}^{\prime}$ & CSR & $\overline{N_{\mathrm{L}}}$ \\
\hline$\overline{\mathrm{m} 1}$ & \multicolumn{2}{|l|}{ Monotonic } & 0.744 & 37.1 & 104 & 6.6 & - & - & - & - & - \\
\hline $\mathrm{m} 2$ & \multicolumn{2}{|l|}{ Monotonic } & 0.688 & 52.2 & 104 & 12.8 & - & - & - & - & - \\
\hline m3 & \multicolumn{2}{|l|}{ Monotonic } & 0.631 & 67.5 & 104 & 16.1 & - & - & - & - & - \\
\hline $\mathrm{m} 4$ & \multicolumn{2}{|l|}{ Monotonic } & 0.586 & 79.6 & 104 & 25 & - & - & - & - & - \\
\hline $\mathrm{m} 5$ & \multicolumn{2}{|l|}{ Monotonic } & 0.644 & 64.0 & 208 & 28.1 & - & - & - & - & - \\
\hline m6 & \multicolumn{2}{|l|}{ Monotonic } & 0.733 & 40.1 & 312 & 26 & - & - & - & - & - \\
\hline m7 & \multicolumn{2}{|l|}{ Monotonic } & 0.730 & 40.9 & 312 & 25.5 & - & - & - & - & - \\
\hline $\mathrm{m} 8$ & \multicolumn{2}{|l|}{ Monotonic } & 0.679 & 54.6 & 312 & 34 & - & - & - & - & - \\
\hline $\mathrm{m} 9$ & \multicolumn{2}{|l|}{ Monotonic } & 0.627 & 68.5 & 312 & 44 & - & - & - & - & - \\
\hline $\mathrm{m} 10$ & \multicolumn{2}{|l|}{ Monotonic } & 0.617 & 71.2 & 312 & 59 & - & - & - & - & - \\
\hline $\mathrm{m} 11$ & \multicolumn{2}{|l|}{ Monotonic } & 0.615 & 71.8 & 312 & 60 & - & - & - & - & - \\
\hline $\mathrm{m} 12$ & \multicolumn{2}{|l|}{ Monotonic } & 0.651 & 62.1 & 416 & 69 & - & - & - & - & - \\
\hline c13 & \multicolumn{2}{|c|}{ Symmetrical loading } & 0.658 & 60.2 & 104 & 14 & 0 & 5.2 & 0 & 0.05 & 18 \\
\hline c14 & \multicolumn{2}{|c|}{ Symmetrical loading } & 0.664 & 58.6 & 208 & 27 & 0 & 5.2 & 0 & 0.025 & 88 \\
\hline c15 & \multicolumn{2}{|c|}{ Symmetrical loading } & 0.670 & 57.0 & 208 & 26 & 0 & 10.4 & 0 & 0.05 & 14 \\
\hline c16 & \multicolumn{2}{|c|}{ Symmetrical loading } & 0.660 & 59.7 & 208 & 28 & 0 & 20.8 & 0 & 0.1 & 2 \\
\hline c17 & \multicolumn{2}{|c|}{ Symmetrical loading } & 0.663 & 58.9 & 312 & 42 & 0 & 15.6 & 0 & 0.05 & 33 \\
\hline c18 & \multicolumn{2}{|c|}{ Symmetrical loading } & 0.662 & 59.1 & 416 & 57 & 0 & 10.4 & 0 & 0.025 & 366 \\
\hline c19 & \multicolumn{2}{|c|}{ Symmetrical loading } & 0.660 & 59.7 & 416 & 57 & 0 & 10.4 & 0 & 0.025 & 300 \\
\hline $\mathrm{c} 20$ & \multicolumn{2}{|c|}{ Symmetrical loading } & 0.638 & 65.6 & 416 & 67 & 0 & 20.8 & 0 & 0.05 & 81 \\
\hline$c 21$ & \multicolumn{2}{|c|}{ Symmetrical loading } & 0.663 & 58.9 & 416 & 57 & 0 & 20.8 & 0 & 0.05 & 62 \\
\hline$c 22$ & \multicolumn{2}{|c|}{ Symmetrical loading } & 0.656 & 60.8 & 416 & 60 & 0 & 20.8 & 0 & 0.05 & 62 \\
\hline $\mathrm{c} 23$ & \multicolumn{2}{|c|}{ Symmetrical loading } & 0.655 & 61.0 & 416 & 60 & 0 & 31.2 & 0 & 0.075 & 10 \\
\hline c24 & Symmetrica & loading & 0.644 & 64.0 & 416 & 65 & 0 & 41.6 & 0 & 0.1 & 3 \\
\hline c25 & Symmetrica & loading & 0.648 & 62.9 & 416 & 65 & 0 & 62.4 & 0 & 0.167 & 1 \\
\hline c26 & Non-symm & stress reversal & 0.629 & 68.0 & 416 & 71 & 5.2 & 10.4 & 0.0125 & 0.025 & 600 \\
\hline $\mathrm{c} 27$ & Non-symm & stress reversal & 0.654 & 61.3 & 416 & 60 & 5.2 & 20.8 & 0.0125 & 0.05 & 57 \\
\hline $\mathrm{c} 28$ & Non-symm & Non-stress reversal & 0.669 & 57.3 & 416 & 53 & 10.4 & 10.4 & 0.025 & 0.025 & 368 \\
\hline c29 & Non-symm & stress reversal & 0.663 & 58.9 & 416 & 56 & 10.4 & 20.8 & 0.025 & 0.05 & 19 \\
\hline c30 & Non-symm & stress reversal & 0.654 & 61.3 & 416 & 60 & 10.4 & 20.8 & 0.025 & 0.05 & 39 \\
\hline c31 & Non-symm & stress reversal & 0.641 & 64.8 & 416 & 66 & 10.4 & 20.8 & 0.025 & 0.05 & 56 \\
\hline c32 & Non-symm & Non-stress reversal & 0.653 & 61.6 & 416 & 61 & 20.8 & 10.4 & 0.05 & 0.025 & 240 \\
\hline c33 & Non-symm & Non-stress reversal & 0.641 & 64.8 & 416 & 57 & 20.8 & 10.4 & 0.05 & 0.025 & 310 \\
\hline c34 & Non-symm & Non-stress reversal & 0.635 & 66.4 & 416 & 71 & 20.8 & 20.8 & 0.05 & 0.05 & 100 \\
\hline c35 & Non-symm & Non-stress reversal & 0.666 & 58.1 & 416 & 55 & 20.8 & 20.8 & 0.05 & 0.05 & 45 \\
\hline c36 & Non-symm & Stress reversal & 0.640 & 65.1 & 416 & 66 & 20.8 & 41.6 & 0.05 & 0.1 & 7 \\
\hline c37 & Non-symm & Non-stress reversal & 0.654 & 61.3 & 416 & 60 & 41.6 & 10.4 & 0.1 & 0.025 & 330 \\
\hline c38 & Non-symm & Non-stress reversal & 0.664 & 58.6 & 416 & 56 & 41.6 & 20.8 & 0.1 & 0.05 & 19 \\
\hline
\end{tabular}

Initial void ratio $e_{0}$ and relative densities $D_{\text {ro }}$ were measured at the corresponding initial effective normal stress $\sigma_{n 0}^{\prime}$; for monotonic loading, the shear stress at phase transformation state $\tau_{\mathrm{pt}}$ was measured based on the experimental results, and for cyclic loading $\tau_{\mathrm{pt}}$ was calculated based on the empirical Equation (2); cyclic shear stress ratio CSR could be expressed by the cyclic shear stress $\tau_{\text {cyc }}$ over the initial effective normal stress $\sigma_{n 0}^{\prime} ; \mathrm{N}_{\mathrm{L}}$ is the number of cycles to liquefaction.

butyl membrane with a thickness of $0.2 \mathrm{~mm}$, itself placed against a stack of rigid circular Tefloncoated thin rings ( $1 \mathrm{~mm}$ each) which maintains a constant cross-sectional area but allowed simple shear deformation (Figure 2(c)). On both sides, the sand is in contact with rough sintered stainless steel plates to prevent any sliding between the pedestals and the specimen. The constant volume condition is ensured by constraining the height of the sample to a constant value after the $K_{0}$-consolidation. Compared to a truly undrained test where the evolution of excess pore pressure can be directly measured, the normal effective stress $\sigma_{n}^{\prime}$ on the horizontal plane continuously varies to fulfil the constant volume condition during simple shear testing. The assumption that the change in the applied normal effective stress is equal to the excess pore which would have developed in a truly undrained test has been validated by Dyvik et al. (1987), and has been applied in extensive laboratory testing during the last two decades.

The experimental campaign consisting of monotonic and cyclic simple shear tests is presented in Table 2. For the cyclic tests, sine cycles with a frequency of $0.05 \mathrm{~Hz}$ were applied. The dry specimens were first consolidated under $K_{0}$-condition up to a given initial effective normal stress $\sigma_{n 0}^{\prime}$. Three series of constant volume simple shear tests were carried out: 
The first series consisted of monotonic simple shear tests, which were performed at different initial effective normal stresses $\left(104 \leq \sigma_{n 0}^{\prime} \leq 416 \mathrm{kPa}\right)$ and different void ratios after consolidation $\left(0.59 \leq e_{0} \leq 0.74\right)$. The objective of this part was to determine the shear stress at phase transformation state $\tau_{\mathrm{pt}}$, for different void ratios after consolidation $e_{0}$ and different initial effective normal stresses $\sigma_{n 0}^{\prime}$.

The second series consisted of symmetrical cyclic simple shear tests (the average shear stress $\tau_{\text {ave }}$ was null). Several tests with different cyclic shear stress amplitudes $\left(5.2 \leq \tau_{\text {cyc }} \leq 62.4 \mathrm{kPa}\right.$ ) and initial normal stresses $\left(104 \leq \sigma_{n 0}^{\prime} \leq 416 \mathrm{kPa}\right)$ on medium dense specimens were performed. The objective of this part was to study the influence of the cyclic shear stress $\tau_{\text {cyc }}$ on the number of cycles to liquefaction $N_{\mathrm{L}}$.

The third series consisted of non-symmetrical cyclic simple shear tests $\left(\tau_{\text {ave }} \neq 0\right)$, with different cyclic shear stress amplitudes $\left(10.4 \leq \tau_{\text {cyc }} \leq 41.6 \mathrm{kPa}\right)$ and different average shear stresses (5.2 $\leq \tau_{\text {ave }} \leq 41.6 \mathrm{kPa}$ ) on medium dense specimens under an effective normal stress $\sigma_{n 0}^{\prime}=416 \mathrm{kPa}$. Two sets of loading conditions, namely shear stress-reversal $\left(\tau_{\text {cyc }}>\tau_{\text {ave }}\right)$ and no shear stressreversal $\left(\tau_{\text {cyc }} \leq \tau_{\text {ave }}\right.$ ), were applied. The objective in this part was to study the influence of the average shear stress $\tau_{\text {ave }}$ on the number of cycles to liquefaction $N_{\mathrm{L}}$.

\section{Test results and interpretation}

\subsection{Monotonic stress-strain behaviour}

Figure 3 shows the stress-strain response of Fontainebleau sand samples during monotonic simple shear testing. The shear strain $\gamma$ is defined as $\gamma=\Delta d / H_{0}$ (where $H_{0}$ is the sample height at the start of the shearing, and $\Delta d$ is the horizontal displacement). Under constant volume condition, the shearing-induced, at first, a decrease of the effective normal stress before the phase transformation state was reached. The extreme points in the shear stress-effective normal stress diagram mark the change from contractancy to dilatancy and therefore, the position of the phase transformation state. Beyond that state, the effective normal stress increased towards the failure line. Figure $3(a, b)$ presents the influence of the void ratio after consolidation $e_{0}$ for a given effective normal stress of $312 \mathrm{kPa}$. The loosest specimen after consolidation exhibits the largest decrease of the effective normal stress. Figure $3(c, d)$ presents the influence of the initial effective normal stress level, from 104 to $416 \mathrm{kPa}$, for a range of relative densities corresponding to a medium density. The friction angle at failure $\phi_{\mathrm{f}}$ is equal to $30^{\circ}$. The phase transformation states are located on a unique straight line passing through the origin, whose slope corresponds to a friction angle of $24^{\circ}$. The PTL delineates two distinct volumetric behaviours (contractancy below PTL, dilatancy between PTL and failure line), which will subsequently govern the evolution of the samples during cyclic shearing. In Figure $3(\mathrm{e}, \mathrm{f})$, the effective normal stress $\left(\sigma_{n}^{\prime}\right)$ and the shear stress $(\tau)$ are normalised by the corresponding initial effective normal stress $\left(\sigma_{n 0}^{\prime}\right)$ and the shear stress at phase transformation state $\left(\tau_{\mathrm{pt}}\right)$, respectively. For the same initial effective normal stress, a smaller void ratio $e_{0}$ corresponds to a larger normalised effective normal stress $\left(\sigma_{n \text {-pt }}^{\prime} / \sigma_{n 0}^{\prime}\right)$ at the phase transformation state. For the same void ratio, the magnitude of the normalised stress at the phase transformation state $\left(\sigma_{n \text {-pt }}^{\prime} / \sigma_{n 0}^{\prime}, \tau / \tau_{\mathrm{pt}}\right)$ is slightly affected by the value of the initial effective normal stress.

The values of the shear stress at phase transformation $\tau_{\mathrm{pt}}$ are plotted in Figure $4(\mathrm{a})$ against the relative density after consolidation $D_{\mathrm{ro}}$, defined in Equation 2 . It can be seen that the shear stress $\tau_{\mathrm{pt}}$ depends on the void ratio $e_{0}$ and on the initial normal effective stress $\sigma_{n 0}^{\prime}$. In Figure $4(\mathrm{~b})$, the shear stress $\tau_{\mathrm{pt}}$ is normalised by the initial effective normal stress $\sigma_{n 0}^{\prime}$ and plotted as a function of $D_{\mathrm{r} 0}$. A non-linear relationship between the void ratio $e_{0}$ and the normalised shear stress $\tau_{\mathrm{pt}} / \sigma_{n 0}^{\prime}$ is obtained and an empirical function can be deduced, which allows us to estimate the shear stress $\tau_{\mathrm{pt}}$, depending on the given parameters $\sigma_{n 0}^{\prime}$ and $e_{0}$ (Equation 2). The parameters $\alpha$ and $\beta$ were calibrated by fitting the experimental data for Fontainebleau sand: $\alpha=0.68$ and $\beta=1.76$. 

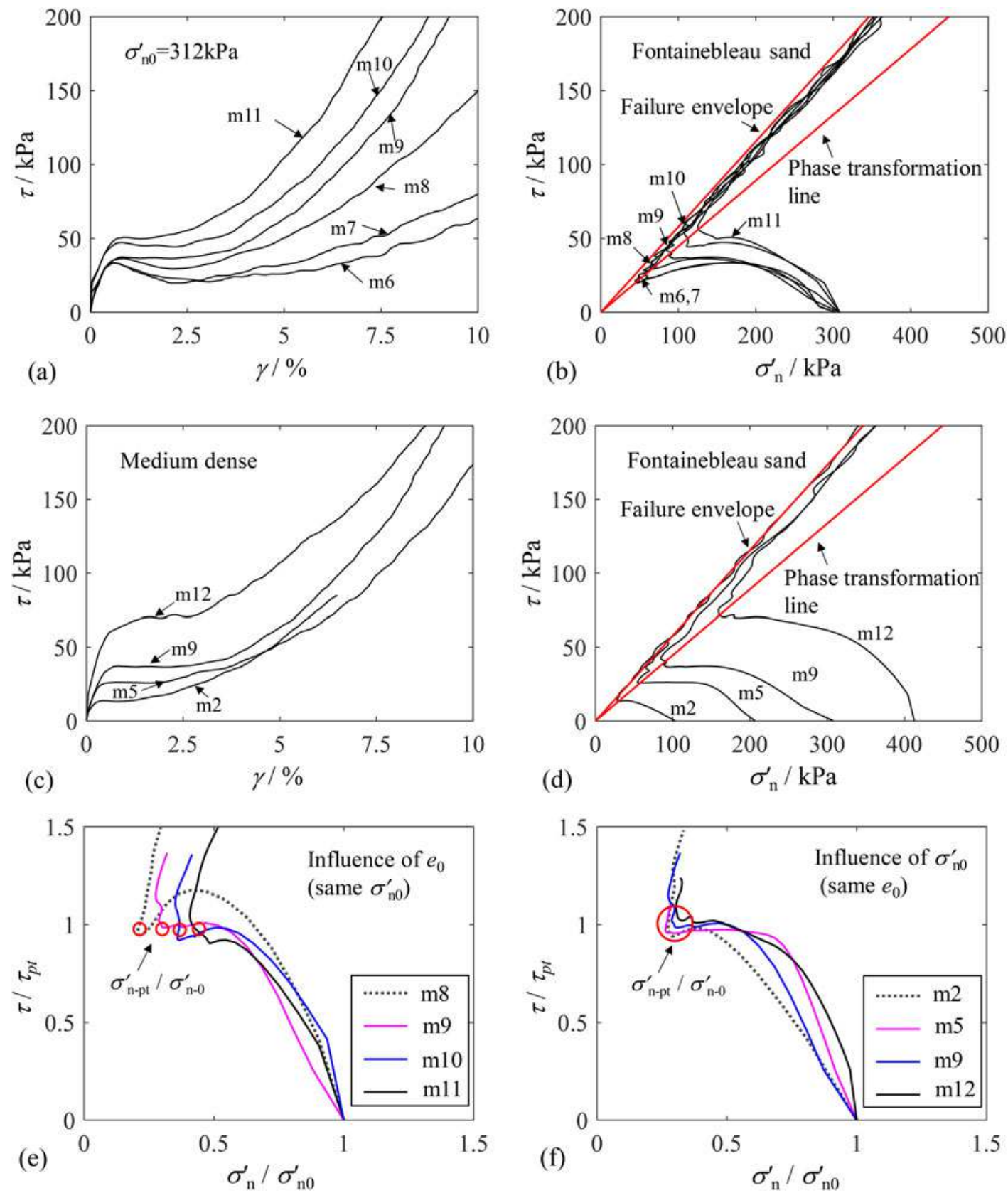

Figure 3. Undrained monotonic test results on Fontainebleau sand: (a) $\gamma-\tau$ with different $e_{0}$; (b) $\sigma_{n}^{\prime}-\tau$ with different $e_{0}$; (c) $\gamma$ - $\tau$ with different $\sigma_{n 0 ;}^{\prime}$ (d) $\sigma_{n}^{\prime}-\tau$ with different $\sigma_{n 0 ;}^{\prime}$ (e) $\sigma_{n}^{\prime} / \sigma_{n 0}^{\prime}-\tau / \tau_{\mathrm{pt}}$ with different $e_{0} ;$ (f) $\sigma_{n}^{\prime} / \sigma_{n 0}^{\prime}-\tau / \tau_{\mathrm{pt}}$ with different $\sigma_{\mathrm{n} 0}^{\prime}$.

$$
\tau_{p t}=\alpha \cdot \sigma_{n 0}^{\prime} \cdot \tan \phi_{p t} \cdot D_{r 0}^{\beta} \quad \text { with } \quad D_{r 0}=\frac{e_{\max }-e_{0}}{e_{\max }-e_{\min }}
$$

\subsection{Symmetrical cyclic loading}

Thirteen constant volume symmetrical cyclic simple shear tests were performed on medium dense Fontainebleau sand specimens under various initial effective normal stresses $\left(\sigma_{n 0}^{\prime}=104\right.$, 

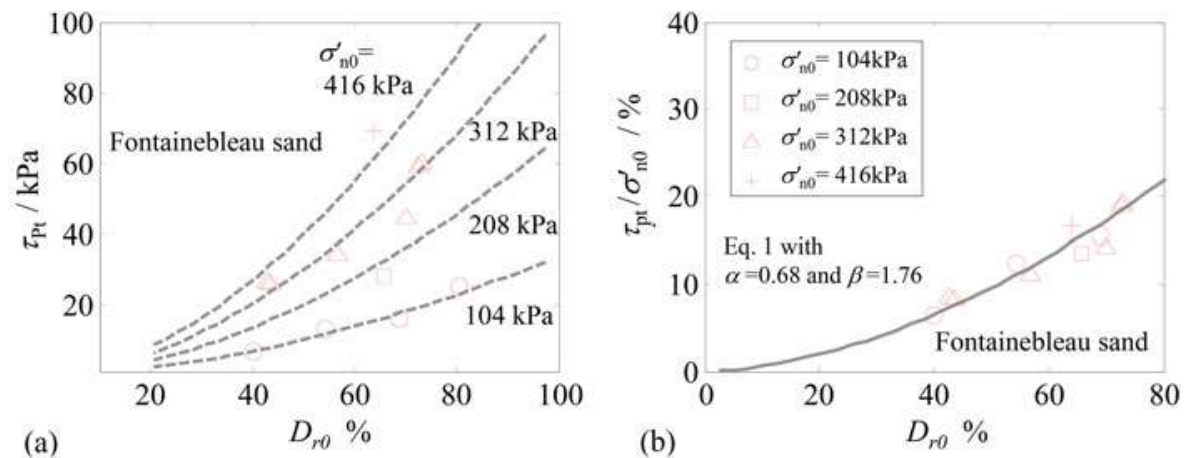

Figure 4. $\tau_{\mathrm{pt}}$ as a function of experimental variables $\sigma_{\mathrm{n} 0}^{\prime}$ and $D_{\mathrm{r} 0}$ : (a) $\tau_{\mathrm{pt}}-D_{\mathrm{r} 0} ;$ (b) $\tau_{\mathrm{pt}} / \sigma_{\mathrm{n} 0^{-}}^{\prime} D_{\mathrm{r} 0}$.
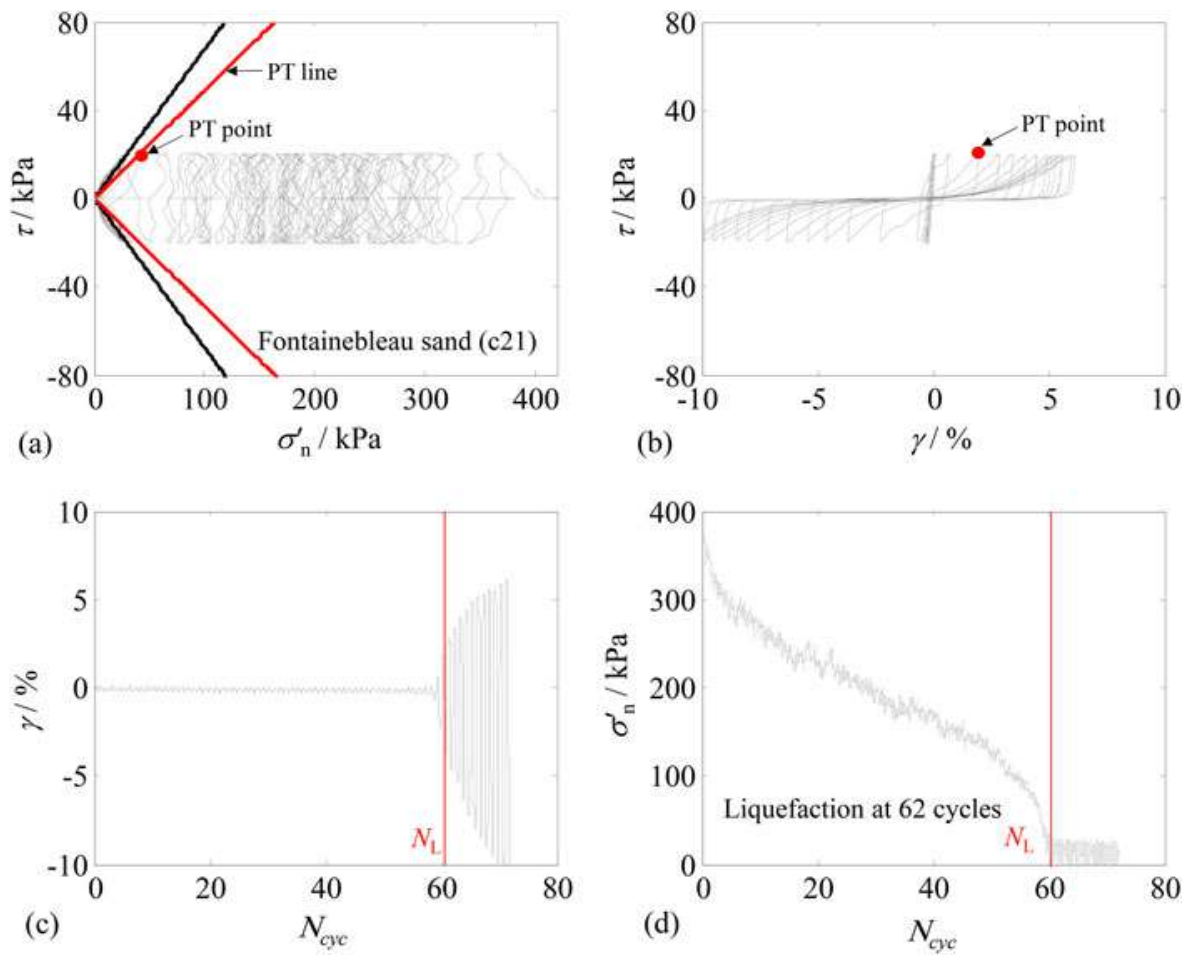

Figure 5. Symmetrical cyclic response of Fontainebleau sand: (a) $\sigma_{\mathrm{n}}^{\prime}-\tau$; (b) $\gamma-\tau$; (c) $N_{\text {cyc }}-\tau$; (d) $N_{\text {cyc }}-\sigma_{n}^{\prime}$.

$208,312,416 \mathrm{kPa}$ ). A typical test result (Test c21: $\tau_{\mathrm{ave}}=0 \mathrm{kPa}, \tau_{\mathrm{cyc}}=20.8 \mathrm{kPa}, \sigma_{\mathrm{no}}^{\prime}=416 \mathrm{kPa}$ ) is presented in Figure 5. Upon reaching the PTL, the effective stress path started to follow a butterfly-shaped loop due to the continuous transition from contractany to dilatancy. It also quickly approached the failure line, which resulted in a rapid generation of large shear strains (Figure $5(\mathrm{a}-\mathrm{c})$ ). The effective normal stress $\sigma_{n}^{\prime}$ decreased with the number of cycles, until reaching a minimum value $\left(\sigma_{\mathrm{n}}^{\prime} \approx 0 \mathrm{kPa}\right)$ when liquefaction occurred (Figure 5(d)). Under this condition, the specimen could no longer sustain any loading (loss of controllability of the test). In this example, the required number of cycles to trigger liquefaction $N_{\mathrm{L}}$ was equal to 62 $\left(N_{\mathrm{L}}=62\right)$. For the undrained cyclic loading, due to the volume change not occurring, the stress-dilatancy relationship associated with the change of effective normal stress. The sand undergoing a degradation of $\sigma_{n}^{\prime}$ is first subjected to an over-consolidation state until the stress 

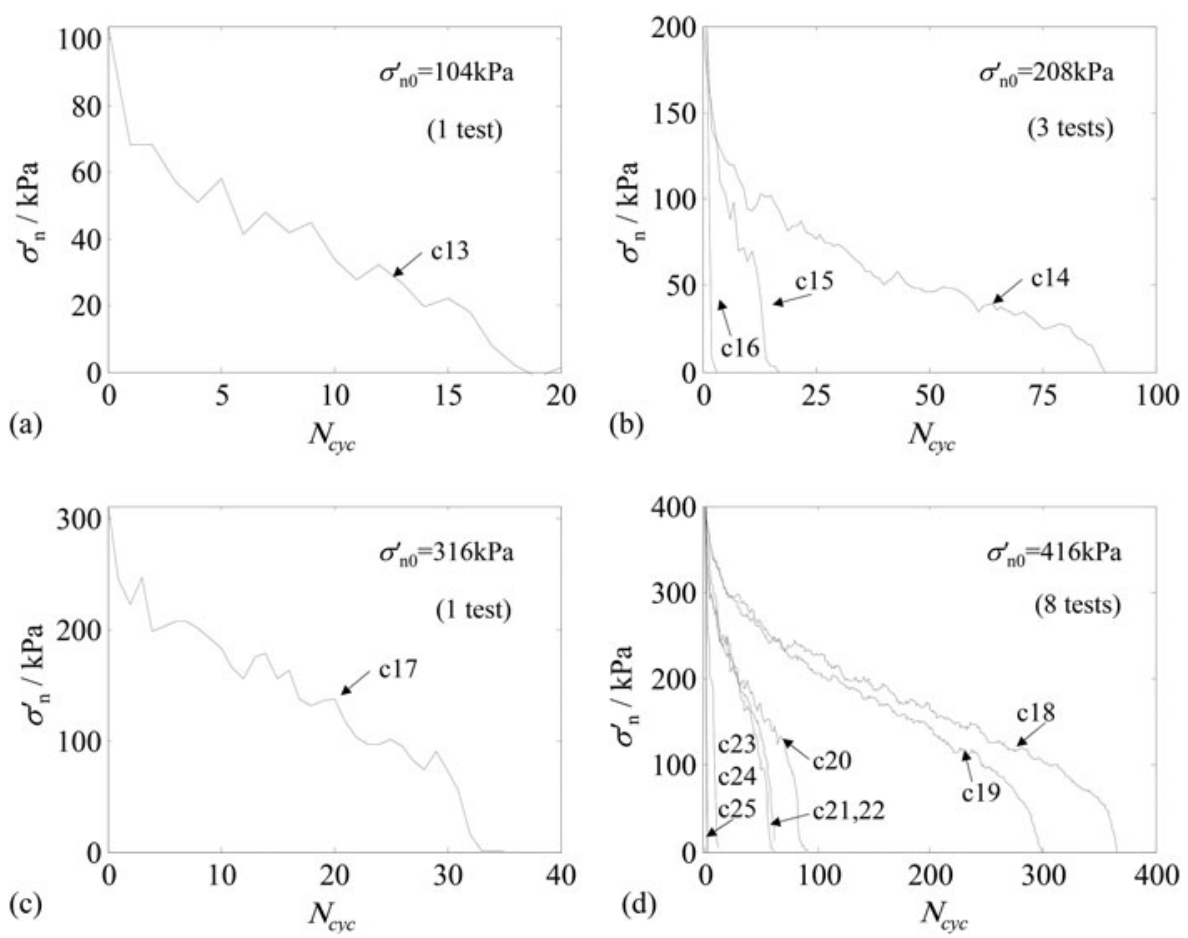

Figure 6. Degradation of effective normal stress under different CSRs: (a) $\sigma_{n 0}^{\prime}=104 \mathrm{kPa}$; (b) $\sigma_{\mathrm{n} 0}^{\prime}=208 \mathrm{kPa}$; (c) $\sigma_{\mathrm{n} 0}^{\prime}=314 \mathrm{kPa}$; (d) $\sigma_{\mathrm{n} 0}^{\prime}=416 \mathrm{kPa}$.

state exceeds the phase transformation stress state where the volumetric strain increment changes from contractive to dilative behaviour. Then, the sand enters the stage of cyclic mobility.

The degradation of the effective normal stress for all the symmetrical cyclic tests has been compiled in Figure 6, as a function of the initial normal effective stress $\sigma_{n 0}^{\prime}$ and for different cyclic shear stresses $\tau_{\text {cyc. }}$. As expected, for a given effective initial normal stress, the number of cycles to liquefaction increased as the cyclic shear stress decreased. Likewise, a higher initial effective normal stress delayed the occurrence of liquefaction (greater $N_{\mathrm{L}}$ ) since the distance between the initial stress state and the corresponding phase transformation state in the $\left(\sigma_{n 0}^{\prime}-\tau\right)$ stress plane was larger. In order to establish a correlation between the cyclic shear stress and the number of cycles to liquefaction, the cyclic shear stress amplitude was normalised by the phase transformation shear stress $\tau_{\mathrm{pt}}$ obtained through monotonic simple shear tests and calculated by Equation (2). The results (points in Figure 7) are plotted versus the number of cycles to liquefaction $N_{L}$. The experimental data are then fitted assuming a power function between $N_{\mathrm{L}}$ and the normalised cyclic shear stress ratio $\tau_{\mathrm{cyc}} / \tau_{\mathrm{pt}}$, as indicated in Equation (3). In the case of Fontainebleau sand, the power $\zeta$ was found equal to 0.27 .

$$
\frac{\tau_{c y c}}{\tau_{p t}}=\frac{1}{N_{\mathrm{L}}^{\zeta}}
$$

\subsection{Non-symmetrical cyclic loading}

Fourteen constant volume non-symmetrical cyclic simple shear tests were performed on medium dense Fontainebleau sand samples with a given initial normal effective stress $\left(\sigma_{n 0}^{\prime}=416 \mathrm{kPa}\right)$. Two loading conditions were imposed: stress reversal $\left(\tau_{\text {cyc }}>\tau_{\text {ave }}\right)$ and no-stress 


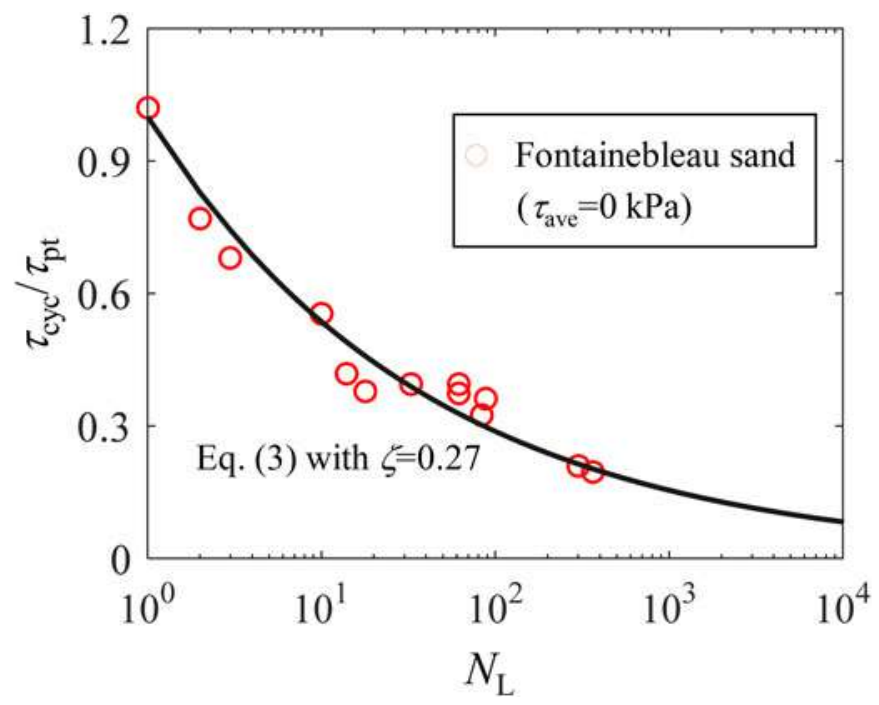

Figure 7. Number of cycles to liquefaction as a function of the normalized cyclic shear stress $\tau_{c y c} d \tau_{p t}$.
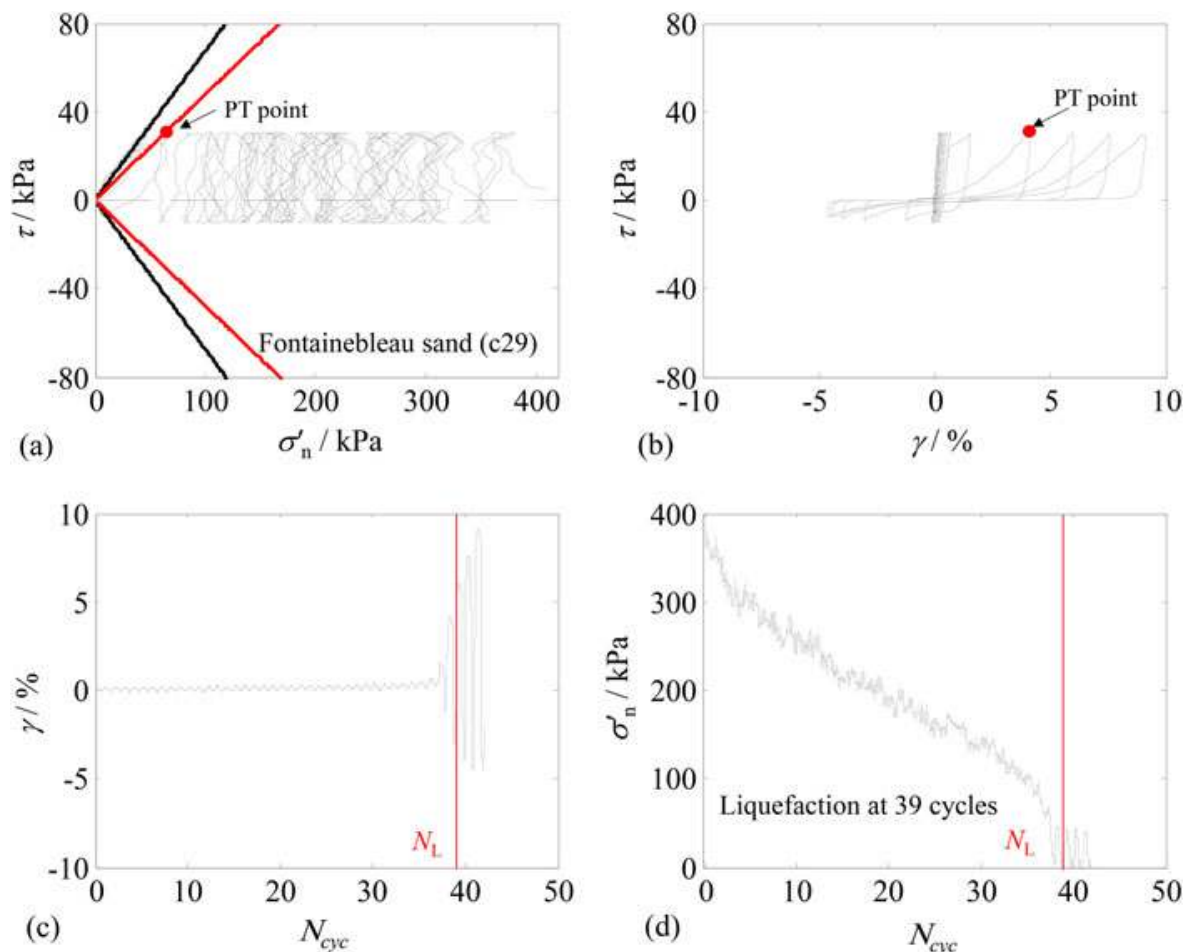

Figure 8. Non-symmetrical cyclic response of Fontainebleau sand with stress reversal loading: (a) $\sigma_{\mathrm{n}}^{\prime}-\tau$; (b) $\gamma-\tau$; (c) $N_{\text {cyc }}-\tau$; (d) $N_{\text {cyc }}-\sigma_{\text {n. }}^{\prime}$.

reversal $\left(\tau_{\mathrm{cyc}}<\tau_{\mathrm{ave}}\right)$ cyclic loading. Figure 8 shows a typical test result (Test c29) for stress reversal cyclic loading $\left(\tau_{\mathrm{cyc}}=20.8 \mathrm{kPa}, \tau_{\text {ave }}=10.4 \mathrm{kPa}, \sigma_{\text {no }}^{\prime}=416 \mathrm{kPa}\right)$. The response was very similar to the one observed in the symmetrical case, except for a small evolution of the average shear strain. The comparison of Figures 5 and 8, for which the unique difference is the value of the average shear stress $(0 \mathrm{kPa}$ for Test c21 in Figure 5 and $10.4 \mathrm{kPa}$ for Test c29 in 

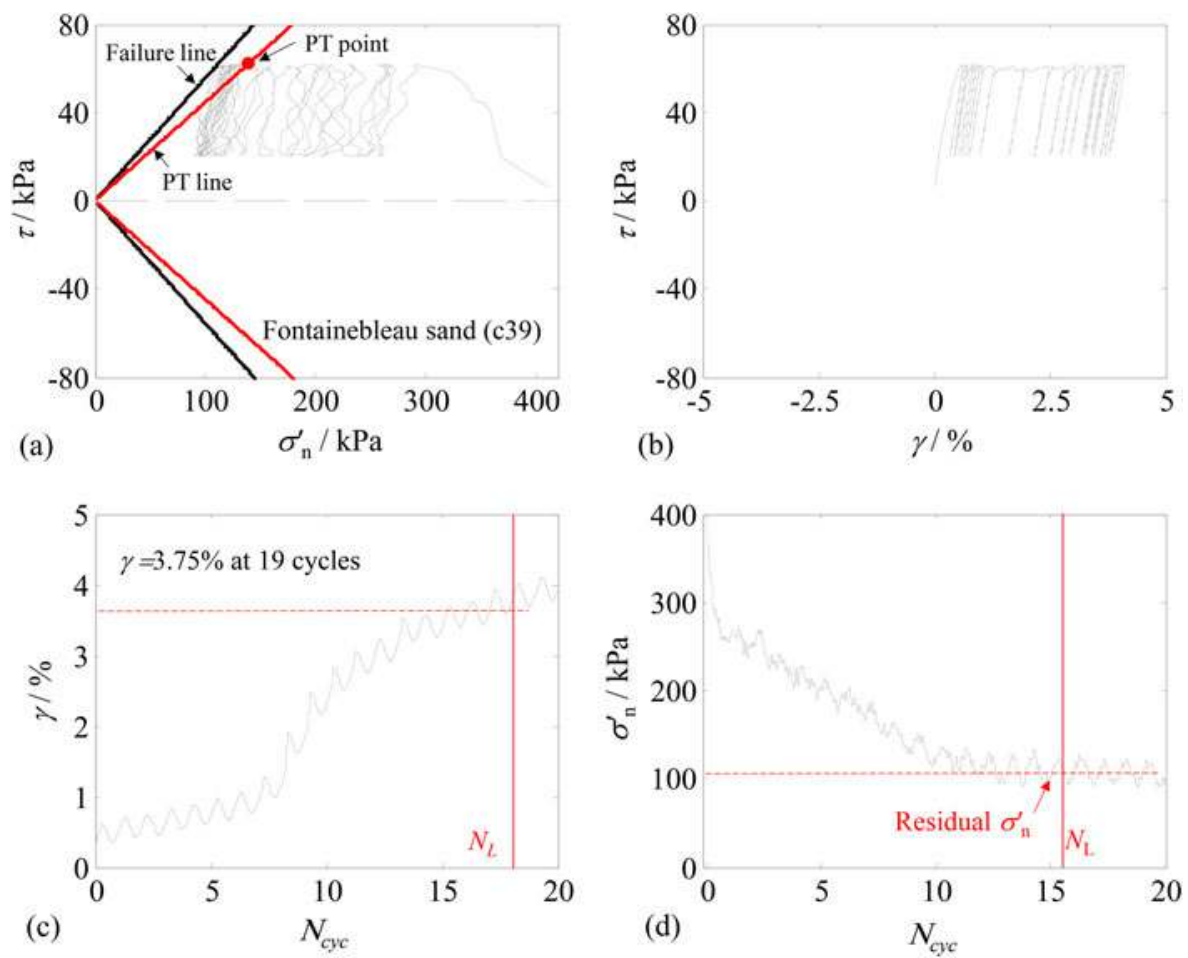

Figure 9. Non-symmetrical cyclic response of Fontainebleau sand with no-stress reversal loading: (a) $\sigma^{\prime}{ }^{-}-\tau$; (b) $\gamma-\tau$; (c) $N_{\text {cyc }}-\tau$; (d) $N_{\text {cyc }}-\sigma_{n}^{\prime}$.

Figure 8), demonstrates that an increase of the average shear stress favours the degradation of the effective normal stress, since the number of cycles to liquefaction was reduced by a factor of about 1/3 (62-39 cycles). Similarly, a typical result of no-stress reversal cyclic loading (Test c39: $\tau_{\text {cyc }}=20.8 \mathrm{kPa}, \tau_{\text {ave }}=41.6 \mathrm{kPa}, \sigma_{\text {n0 }}^{\prime}=416 \mathrm{kPa}$ ) is reported in Figure 9. All the test loading conditions except the value of the average shear stress were the same, as in Tests c21 and c29 previously discussed. The instability, corresponding to a cyclic mobility mechanism, occurred at a smaller number of cycles (between 15 and 20 cycles), due to the proximity of the stress path to both the PT and failure lines. The effective normal stress reached a residual value $(100 \mathrm{kPa}$ in the case of Test c39). For this type of test, the instability was determined by the condition of the effective normal stress reaching a residual value $\left(\sigma_{n-}^{\prime}\right.$ residual $=98 \mathrm{kPa}$ ).

Figure 10 summarises all the results relative to non-symmetrical cyclic tests under the same initial effective normal stress of $416 \mathrm{kPa}$ with different average shear stresses. The results corresponding to the stress reversal condition for which the effective normal stresses decreased to zero, i.e. the liquefied state, were plotted in red. For the no-stress reversal condition, the effective normal stress decreased to a residual stress. For a better comparison of the results obtained under these two conditions, the number of cycles to instability (liquefaction or cyclic mobility) was defined by the effective normal stress reaching the limited final value. The degradation of the effective normal stress for all the non-symmetrical cyclic tests was plotted as a function of the cyclic shear stress $\tau_{\text {cyc }}$ and the average shear stress $\tau_{\text {ave }}$ in Figure 10 . As expected, for a given average shear stress, the number of cycles to liquefaction increased with the decrease of the cyclic shear stress.

Figure 11(a) presents the hysteresis loops of non-stress reversal cyclic loading corresponding to the cyclic mobility final state which were used to calibrate the value of the residual effective 



Figure 10. Degradation of effective normal stress under different average shear stress $\tau_{\text {ave }}$ : (a) $\tau_{\text {ave }}=5.2 \mathrm{kPa}$; (b) $\tau_{\text {ave }}=10.4 \mathrm{kPa}$; (c) $\tau_{\text {ave }}=20.8 \mathrm{kPa}$; (d) $\tau_{\text {ave }}=41.6 \mathrm{kPa}$.


Figure 11. Evaluation of effective residual normal stress in no-stress reversal cyclic loading: (a) hysteresis loops of instability; (b) fitting line for residual effective normal stress.

normal stress $\left(\sigma_{n \text {-residual }}^{\prime}\right)$. The values of $\sigma_{n \text {-residual }}^{\prime}$ corresponding to the maximum shear stress $\tau_{\max }$ which is equal to the average shear stress $\tau_{\text {ave }}$ plus the cyclic shear stress $\tau_{\text {cyc }}$ are shown in Figure 11(b) for nine no-stress reversal cyclic tests. An empirical expression could be suggested to evaluate the residual effective normal stress:



where $\chi$ is a parameter obtained by fitting the data of non-stress reversal cyclic tests $(\chi=0.77$ for Fontainebleau sand); $\tau_{\max }$ is the maximum shear stress equal to $\tau_{\mathrm{ave}}+\tau_{\mathrm{cyc}} ; \phi_{\mathrm{f}}$ is the friction angle at failure. A good agreement could be obtained between calculated results (dash blue line) and measurements (red symbols). 


\section{Evaluation of the degradation of the effective normal stress}

\subsection{Number of cycles to liquefaction}

The experimental data were mapped on a 3D plot, where two axes represent the stress ratios $\tau_{\mathrm{cyc}} / \tau_{\mathrm{pt}}$ and $\tau_{\mathrm{ave}} / \tau_{\mathrm{pt}}$, and the third one, the number of cycles to instability (liquefaction or cyclic mobility) (Figure 12). This plot can be used to describe the cyclic resistance of Fontainebleau sand. For a constant level of normalised average shear stress $\left(\tau_{\text {ave }} / \tau_{\text {pt }}\right)$, the number of cycles to instability decreases with the increase of the normalised cyclic shear stress $\left(\tau_{\text {cyc }} / \tau_{\mathrm{pt}}\right)$. Inversely, for a constant level of normalised cyclic shear stress $\left(\tau_{\mathrm{cyc}} / \tau_{\mathrm{pt}}\right)$, the number of cycles to instability decreases with the increase of the normalised average shear stress $\left(\tau_{\text {ave }} / \tau_{\text {pt }}\right)$.

In order to formulate an expression for the number of cycles to instability, all the couples of normalised stresses $\left(\tau_{\mathrm{ave}} / \tau_{\mathrm{pt}}, \tau_{\mathrm{cyc}} / \tau_{\mathrm{pt}}\right)$ were reported in a diagram of stability shown in Figure 13(a). The space is then delimited by the diagonal corresponding to a failure at the first cycle. Instabilities reached at a higher number of cycles $N_{\mathrm{L}}$ fell on straight lines whose slope $K$ decreased with $N_{\mathrm{L}}$, as shown in Figure 13(a). The slope $K$ can be approximated by:

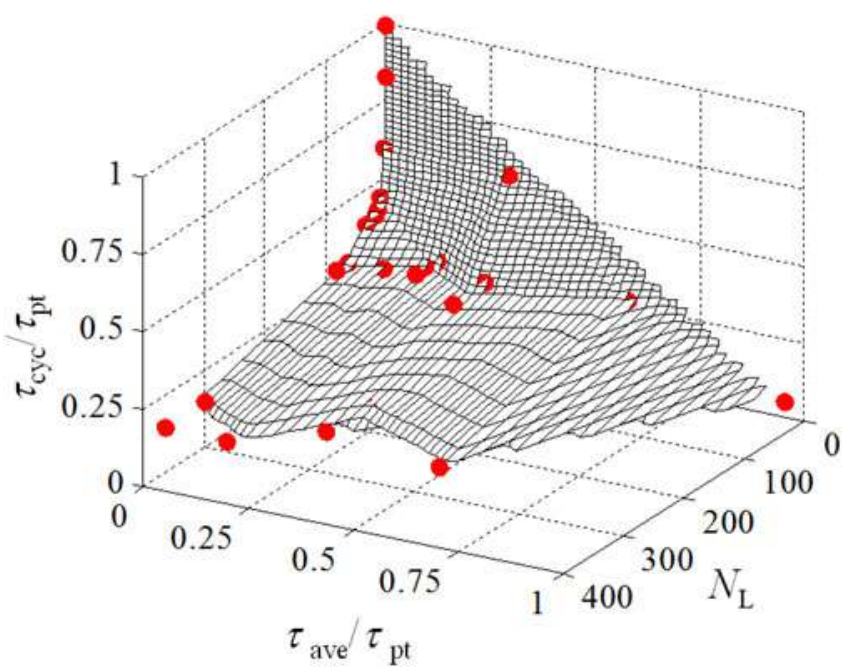

Figure 12. Cyclic resistance surface for cyclic simple shear tests on Fontainebleau sand.


Figure 13. Cyclic resistance diagram for cyclic simple shear tests on Fontainebleau sand: (a) relationship between $\tau_{\mathrm{cyc}} / \tau_{\mathrm{pt}}$ and $\tau_{\text {ave }} / \tau_{\text {pt }}$ (b) relationship between $K$ and $N_{\mathrm{L}}$. 


$$
K=\frac{\tau_{c y c} / \tau_{p t}}{1-\tau_{\text {ave }} / \tau_{p t}}=\frac{\tau_{c y c}}{\tau_{p t}-\tau_{\text {ave }}}
$$

Figure 13(b) correlates the calculated values of $K$ and the corresponding values of $N_{\mathrm{L}}$ which can be expressed by:

$$
N_{L}=\mu \cdot\left(\frac{\tau_{c y c}}{\tau_{p t}-\tau_{a v e}}\right)^{-\psi}
$$

where $\mu$ and $\psi$ are parameters obtained by fitting the experimental results $(\mu=1.396, \psi=3.505$ for Fontainebleau sand).

The diagram in Figure 13(a) can be used to predict the number of cycles to instability (Jardine et al., 2005; Tsuha et al., 2012). The influence of the average shear stress and of the cyclic shear stress has been taken into account in Equation (5), whereas the link between cyclic and monotonic responses of sand is obtained by the variable $\tau_{\mathrm{pt}}$ calibrated by Equation (2), the function of the void ratio $e$ and of the initial effective normal stress $\sigma_{n 0}^{\prime}$.

\subsection{Degradation of effective normal stress}

During stress-controlled constant volume cyclic simple shear testing, the effective normal stress $\sigma_{n}^{\prime}$ decreases from its initial value either to zero or to a residual value. In agreement with the empirical expression of the pore pressure evolution suggested by Seed and Idriss (1971), the degradation of the effective normal stress can be expressed by the following relation:

$$
\frac{\sigma_{n}^{\prime}-\sigma_{n-\text { residual }}^{\prime}}{\sigma_{n 0}^{\prime}-\sigma_{n-\text { residual }}^{\prime}}=\frac{2}{\pi} \arccos \left(\frac{N}{N_{L}}\right)^{\frac{1}{\theta}} ; \quad\left(\text { if } \tau_{\text {ave }}<\tau_{c y c}, \sigma_{n-\text { residual }}^{\prime}=0\right)
$$

where $N$ is the current number of cycles and $\theta$ is a material parameter.

To identify the material parameter $\theta$, the effective normal stress $\sigma_{n}^{\prime}$ normalised by its initial value $\sigma_{\text {no }}^{\prime}$ was represented as a function of the normalised number of cycles to instability $\left(N / N_{\mathrm{L}}\right)$, as shown in Figure 14. 6 experimental results (Tests c19, c20, c23, c26, c28 and c32) with different initial effective normal stresses, different cyclic shear stresses and different average shear stresses were selected to verify the empirical equation. The fitting of Equation (7) with experimental data led to a value $\theta=3.4$ for Fontainebleau sand. By combining Equations (6) and (7),



Figure 14. Normalized effective normal stress against normalized number of cycles to liquefaction. 
the following relationship can be proposed:

$$
\frac{\sigma_{n}^{\prime}-\sigma_{n-\text { residual }}^{\prime}}{\sigma_{n 0}^{\prime}-\sigma_{n-\text { residual }}^{\prime}}=\frac{2}{\pi} \cdot \arccos \left(\frac{1}{\mu} \cdot N \cdot\left(\frac{\tau_{c y c}}{\tau_{p t}-\tau_{a v e}}\right)^{\psi}\right)^{\frac{1}{\theta}}
$$

where $\sigma_{\text {n-residual }}^{\prime}=0 \mathrm{kPa}$ in the condition of cyclic stress reversal $\left(\tau_{\text {cyc }}>\tau_{\text {ave }}\right)$ and $\sigma_{\text {n-residual }}^{\prime}$ being calculated by using Equation (4) in the condition of no-stress reversal ( $\left.\tau_{\text {cyc }} \leq \tau_{\text {ave }}\right)$.

\subsection{Calibration procedure}

The calibration procedure for estimating the degradation of the normal effective stress is presented in Figure 15. Three successive steps are indicated in the calibration chart (1) an expression of the shear stress at the phase transformation state needs be obtained according to the results of monotonic testing (Equation (2)); (2) a cyclic resistance diagram ( $\tau_{\mathrm{ave}} / \tau_{\mathrm{pt}}, \tau_{\mathrm{cyc}} / \tau_{\mathrm{pt}}, N_{\mathrm{L}}$ ) for predicting the number of cycles to liquefaction is plotted based on the cyclic test results (with different cyclic shear stresses and average shear stresses) in order to calibrate the parameters in Equation (6); (3) the effective normal stress degradation is then calculated in order to calibrate Equations (7) and (8).

This analytical formulation can be easily used in practice to analyse the degradation of the shaft capacity for pile design. From this calibration procedure, a minimum of eight tests have to be considered for determining the material parameters, including at least three monotonic tests with different void ratios to determine the phase transformation state, three symmetrical cyclic loading tests with different cyclic stress amplitudes $\tau_{\text {cyc }}$ and 2 non-symmetrical cyclic loading tests with different average shear stresses $\tau_{\text {ave }}$ to study the degradation of the effective normal stress with the number of cycles.

In order to validate the whole procedure, simple shear tests on Fraser River sand (Sivathayalan, 1994) and Quiou carbonate sand (Porcino, Caridi, \& Ghionna, 2008), and triaxial tests on Karlsruhe sand (Wichtmann \& Triantafyllidis, 2016a, 2016b) were selected. The physical properties of these three sands are presented in Table 3.

The normalised shear stresses at PTL $\left(\tau_{\mathrm{pt}} / \sigma_{\text {no }}^{\prime}\right.$ for simple shear tests and $q_{\mathrm{pt}} / 2 p^{\prime}{ }_{0}$ for triaxial tests) were plotted against the corresponding relative densities in Figure 16 . The curves of Equation (2) as solid lines were fitted from the experimental data and the deduced parameters are given in Table 3. The cyclic stability diagram for calibrating the number of cycles to

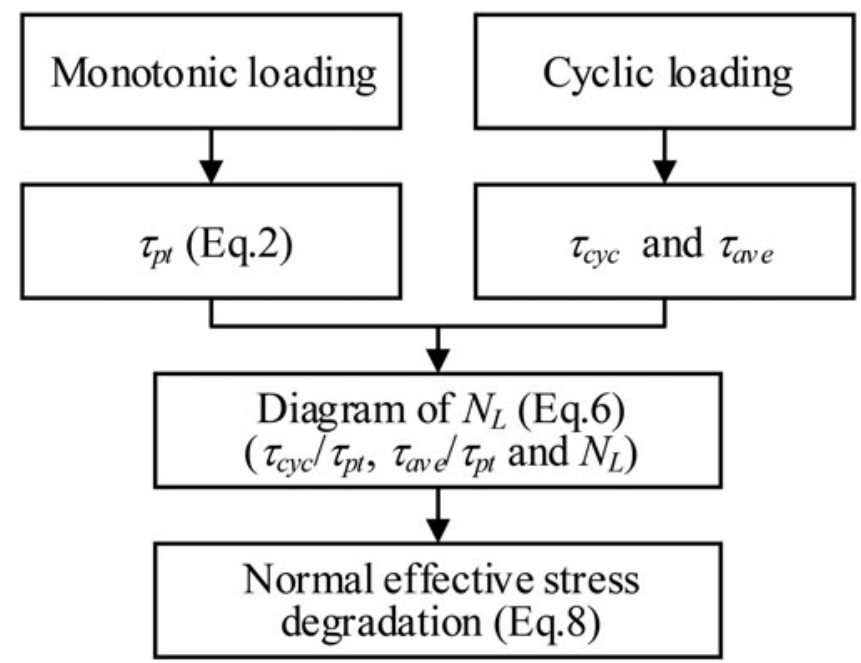

Figure 15. Calibration procedure for the degradation of the effective normal stress. 
Table 3. Physical properties of three studied sands.

\begin{tabular}{lccccc}
\hline Material & $D_{50}(\mathrm{~mm})$ & $C_{\mathrm{u}}$ & $G_{\mathrm{s}}$ & $e_{\max }$ & $e_{\min }$ \\
\hline Fraser river sand & 0.30 & 1.6 & 2.72 & 1.000 & 0.680 \\
Quiou sand & 0.65 & 2.8 & 2.70 & 1.169 & 0.763 \\
Karlsruhe sand & 0.14 & 1.5 & 2.70 & 1.054 & 0.677 \\
\hline
\end{tabular}
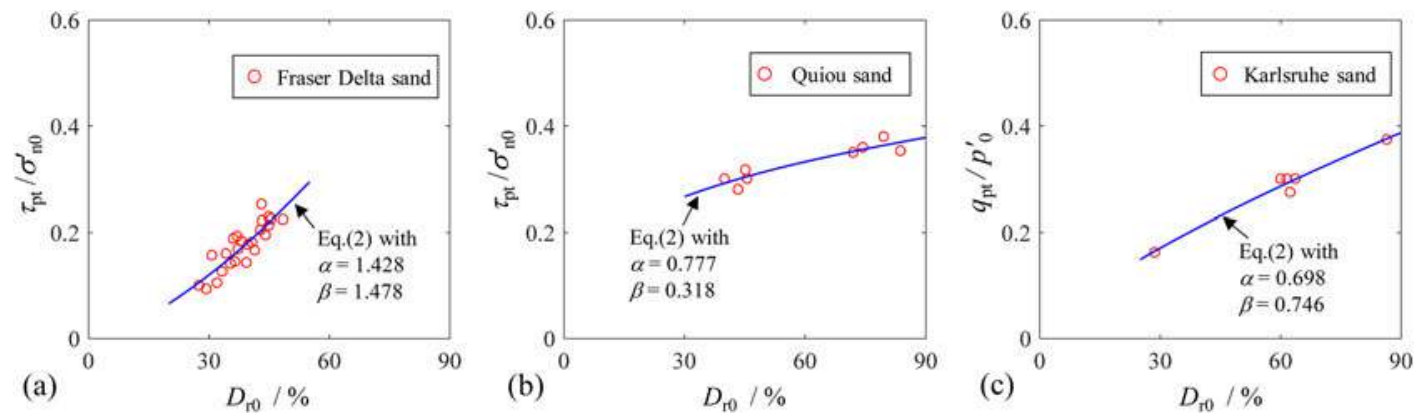

Figure 16. Equation (2) calibration procedure: (a) Fraser River sand; (b) Quiou sand; (c) Karlsruhe sand.



(a)



(b)

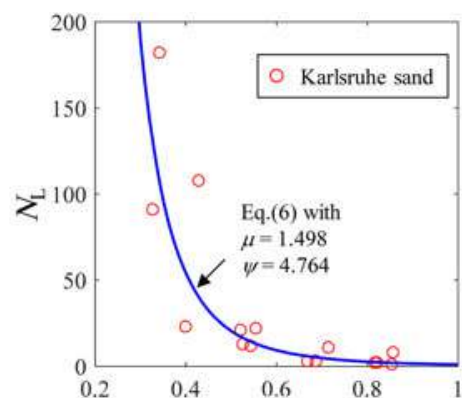

(c)

K

Figure 17. Equation (6) calibration procedure: (a) Fraser River sand; (b) Quiou sand; (c) Karlsruhe sand.

Table 4. Parameters of Equations (2) and (6) with different sands.

\begin{tabular}{lllccc}
\hline Material & $\alpha$ & $\beta$ & $\phi_{\mathrm{pt}}\left({ }^{\circ}\right)$ & $\mu$ & $\psi$ \\
\hline Fontainebleau sand & 0.68 & 1.76 & 24 & 1.396 & 3.505 \\
Fraser river sand & 1.233 & 1.478 & 30 & 3.183 & 2.787 \\
Quiou sand & 0.767 & 0.318 & 27 & 1.004 & 4.353 \\
Karlsruhe sand & 0.738 & 0.746 & 29.6 & 1.498 & 4.764 \\
\hline
\end{tabular}

instability is shown in Figure 17. The parameters $\mu$ and $\psi$ could be obtained by fitting the experimental results as shown in Table 4. Therefore, the behaviour of different sands (quartz sand and carbonate sand) for different loading conditions (simple shear and triaxial loading) can be well expressed by Equations (2) and (6).

\subsection{Validation of the suggested relationship}

The calibration procedure has provided the following parameters for Fontainebleau sand: $\alpha=0.68, \beta=1.76, \mu=1.396, \psi=3.505, \theta=3.4$. The tests presented in Table 2 can be considered as the training tests aimed to determine these parameters. Six complementary tests with different loading conditions were selected and simulated to validate the performance of Equation (8). As shown in Figure 18(a), the results can be well predicted for different loading conditions including symmetrical cyclic loadings with different $\tau_{\text {cyc }}$ (Tests c19, c20 and c23) and non- 

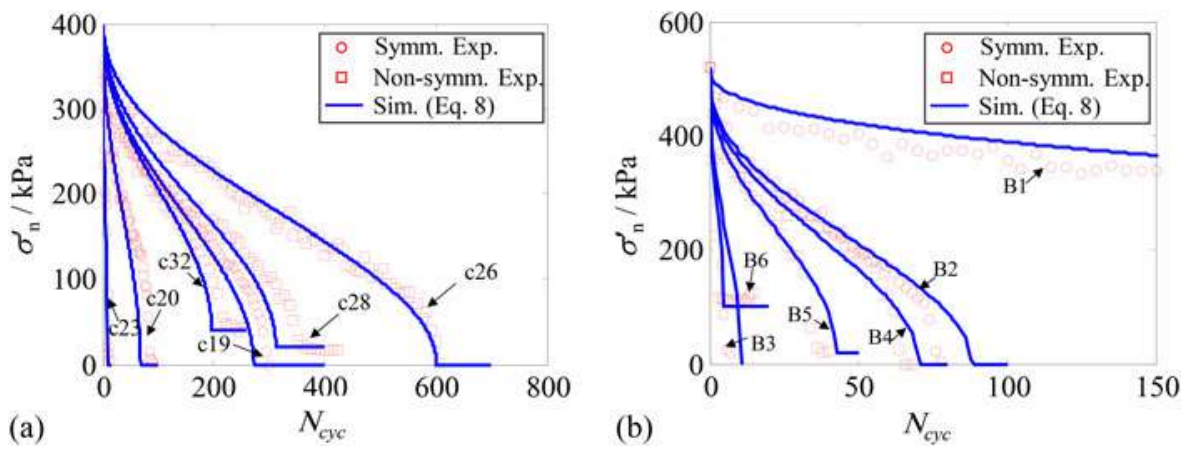

Figure 18. Comparisons between simulations and experiments on Fontainebleau sand: (a) training tests; (b) additional tests.

Table 5. Summary of additional tests on Fontainebleau sand $\left(\sigma_{n 0}^{\prime}=500 \mathrm{kPa}\right)$.

\begin{tabular}{|c|c|c|c|c|c|c|c|}
\hline Test No. & $e_{0}$ & $\tau_{\text {ave }}(\mathrm{kPa})$ & $\tau_{\text {cyc }}(\mathrm{kPa})$ & $\tau_{\mathrm{ave}} / \sigma_{\mathrm{n} 0}^{\prime}$ & CSR & $\tau_{\mathrm{pt}}(\mathrm{kPa})$ & $N_{\mathrm{L}}$ \\
\hline B1 & 0.619 & 0 & 12.5 & 0 & 0.025 & 85.5 & 1015 \\
\hline B2 & 0.626 & 0 & 25 & 0 & 0.05 & 81.6 & 74 \\
\hline B3 & 0.612 & 0 & 50 & 0 & 0.1 & 89.6 & 4 \\
\hline B4 & 0.613 & 12.5 & 25 & 0.025 & 0.05 & 89.0 & 64 \\
\hline B5 & 0.609 & 25 & 25 & 0.05 & 0.05 & 91.3 & 36 \\
\hline B6 & 0.619 & 50 & 25 & 0.1 & 0.05 & 85.5 & 1 \\
\hline
\end{tabular}

symmetrical cyclic loadings with different $\tau_{\text {ave }}$ (Tests c26, c28, and c32). To confirm the pertinence of this equation, a series of additional tests on Fontainebleau sand was performed at a consolidation stress level $\sigma_{n 0}^{\prime}=500 \mathrm{kPa}$ with different loading paths including cyclic shear stresses from 12.5 to $50 \mathrm{kPa}$ and average shear stresses from 0 to $50 \mathrm{kPa}$ (Table 5). The results of these additional tests are presented in Figure 18(b), showing a behavior similar to the one obtained from the results of the training tests reported in Table 2. All additional tests were also simulated by Equation (8) to verify the accuracy of the analytical method for predicting the mechanical behaviour of given sand. Figure 18(b) presents the comparison between the calculated effective normal stress (solid blue line) and the experimental data (red symbols). It demonstrates that Equation (8) can successfully describe the evolution of the effective normal stress for a large range of average shear stresses and cyclic shear stresses.

\section{Conclusions}

The aim of the article has been to develop an analytical method for predicting the degradation of the effective normal stress of a soil element adjacent to a pile shaft under cyclic loading. The development of the analytical formulation was supported by a series of constant volume monotonic and cyclic simple shear tests performed on Fontainebleau sand specimens.

Monotonic simple shear tests on Fontainebleau sand with different void ratios and different initial normal effective stresses were first performed, allowing an empirical expression for calculating the shear stress at the phase transformation state to be suggested.

Then, cyclic simple shear tests were conducted under different initial effective normal stresses, cyclic shear stresses, and average shear stresses. Based on these experimental results, a cyclic resistance diagram was obtained, providing information concerning the number of cycles necessary to reach instability as a function of cyclic and average shear stress levels. The shear stress at the phase transformation state took into account the influence of void ratio and initial effective normal stress on the number of cycles to instability.

A calibration procedure for predicting the degradation of the effective normal stress was proposed. Following this procedure, an analytical expression to evaluate the normal effective stress 
degradation was developed with the following variables: void ratio, initial effective normal stress, cyclic shear stress, average shear stress and number of cycles. A series of additional tests including loading paths with different average shear stresses and cyclic shear stresses verified the proposed analytical expression. All comparisons between experimental results and simulations indicated that the proposed method is capable of predicting the degradation of the effective normal stress under constant volume cyclic shear loading.

\section{Disclosure statement}

No potential conflict of interest was reported by the authors.

\section{Funding}

The research described was supported by the French National Research Agency (ANR SOLCYP), the National Natural Science Foundation of China (51579179), and the Region Pays de la Loire of France (project RI-ADAPTCLIM).

\section{References}

Aghakouchak, A., Sim, W. W., \& Jardine, R. J. (2015). Stress-path laboratory tests to characterise the cyclic behaviour of piles driven in sands. Soils and Foundations, 55(5), 917-928. doi:10.1016/j.sandf.2015.08.001

Andersen, K. H. (2009). Bearing capacity under cyclic loading-offshore, along the coast, and on land. The $21 \mathrm{st}$ Bjerrum lecture presented in Oslo, 23 November 2007 Canadian Geotechnical Journal, 46(5), 513-535. doi: 10.1139/T09-003

Andria-Ntoanina, I., Canou, J., \& Dupla, J. (2010). Caractérisation mécanique du sable de Fontainebleau NE34 à I'appareil triaxial sous cisaillement monotone. France: Laboratoire Navier-Géotechnique. CERMES, ENPC/LCPC.

Bjerrum, L., \& Landva, A. (1966). Direct simple-shear tests on a Norwegian quick clay. Géotechnique, 16(1), 1-20. doi: 10.1680/geot.1966.16.1.1

Dief, H. M., \& Figueroa, J. L. (2007). Liquefaction assessment by the unit energy concept through centrifuge and torsional shear tests. Canadian Geotechnical Journal, 44(11), 1286-1297. doi:10.1139/T07-059

Dupla, J., \& Canou, J. (1994). Caractérisation mécanique du sable de Fontainebleau apartir d'essais triaxiaux de compression et d'extension. Rapport Interne CLOUTERRE II, CERMES-ENPC, Paris.

Dyvik, R., Berre, T., Lacasse, S., \& Raadim, B. (1987). Comparison of truly undrained and constant volume direct simple shear tests. Géotechnique, 37(1), 3-10. doi:10.1680/geot.1987.37.1.3

Fakharian, K., \& Evgin, E. (1997). Cyclic simple-shear behavior of sand-steel interfaces under constant normal stiffness condition. Journal of Geotechnical and Geoenvironmental Engineering, 123(12), 1096-1105. doi:10.1061/ (ASCE)1090-0241(1997)123:12(1096)

Gaudin, C., Schnaid, F., \& Garnier, J. (2005). Sand characterization by combined centrifuge and laboratory tests. International Journal of Physical Modelling in Geotechnics, 5(1), 42-56. doi:10.1680/ijpmg.2005.050104

Gavin, K., Igoe, D., \& Doherty, P. (2011). Piles for offshore wind turbines: A state of the art review. Geotechnical Engineering, 164(4), 245-256 doi:10.1680/geng.2011.164.4.245

Georgiannou, V., \& Tsomokos, A. (2008). Comparison of two fine sands under torsional loading. Canadian Geotechnical Journal, 45(12), 1659-1672. doi:10.1139/T08-083

Green, R., Mitchell, J., \& Polito, C. (2000). An energy-based excess pore pressure generation model for cohesionless soils. In D.W. Smith, J.P. Carter (Eds.) Proceedings of the John Booker Memorial Symposium (pp. 16-17). Rotterdam, Netherlands: A.A. Balkema Publishers.

Gu, C., Wang, J., Cai, Y. Q., \& Guo, L. (2014). Influence of cyclic loading history on small strain shear modulus of saturated clays. Soil Dynamics and Earthquake Engineering, 66, 1-12 doi:10.1016/j.soildyn.2014.06.027

Gu, C., Wang, J., Cai, Y. Q., Sun, L., Wang, P., \& Dong, Q. Y. (2016). Deformation characteristics of overconsolidated clay sheared under constant and variable confining pressure. Soils and Foundations, 56(3), 427-439. doi:10.1016/ j.sandf.2016.04.009

Hyodo, M., Murata, H., Yasufuku, N., \& Fujii, T. (1991). Undrained cyclic shear strength and residual shear strain of saturated sand by cyclic triaxial tests. Soils and Foundations, 31(3), 60-76. doi:10.3208/sandf1972.31.3_60

Ishibashi, I., Sherif, M. A., \& Cheng, W. L. (1982). The effects of soil parameters on pore-pressure-rise and liquefaction prediction. Soils and Foundations, 22(1), 39-48. doi:10.3208/sandf1972.22.39

Ishibashi, I., Sherif, M., \& Tsuchiya, C. (1977). Pore-pressure rise mechanism and soil liquefaction. Soils and Foundations, 17(2), 17-27. doi:10.3208/sandf1972.17.2_17 
Jardine, R., Chow, F., Overy, R., \& Standing, J. (2005). ICP design methods for driven piles in sands and clays. London: Thomas Telford.

Jardine, R., \& Standing, J. (2012). Field axial cyclic loading experiments on piles driven in sand. Soils and foundations, 52(4), 723-736. doi:10.1016/j.sandf.2012.07.012

Jardine, R., Standing, J., \& Health and Safety Executive, London. (2000). Pile load testing performed for HSE cyclic loading study at dunkirk, France (Vol. 1). Offshore Technology Report-Health And Safety Executive Oto. Merseyside, England: Health and Safety Executive.

Jin, Y. F., Yin, Z. Y., Zhang, D. M., \& Huang, H. W. (2015). Unified modelling of monotonic and cyclic behaviours for sand and clay. Acta Mechanica Solida Sinica, 28(2), 111-132. doi:10.1016/S0894-9166(15)30001-X

Konstadinou, M., \& Georgiannou, V. (2014). Prediction of pore water pressure generation leading to liquefaction under torsional cyclic loading. Soils and Foundations, 54(5), 993-1005. doi:10.1016/j.sandf.2014.09.010

Krishnaswamy, N., \& Thomas Isaac, N. (1995). Liquefaction analysis of saturated reinforced granular soils. Journal of Geotechnical Engineering, 121(9), 645-651. doi:10.1061/(ASCE)0733-9410(1995)121:9(645)

Lambe, T. W., \& Whitman, R. V. (1969). Soil mechanics, series in soil engineering. Hoboken, NJ: Jhon Wiley \& Sons.

Law, K. T., Cao, Y., \& He, G. (1990). An energy approach for assessing seismic liquefaction potential. Canadian Geotechnical Journal, 27(3), 320-329. doi:10.1139/t90-043

Mitchell, R. J., \& Dubin, B. I. (1986). Pore pressure generation and dissipation in dense sands under cyclic loading. Canadian Geotechnical Journal, 23(3), 393-398. doi:10.1139/t86-055

Mohtar, C. E., Bobet, A., Drnevich, V., Johnston, C., \& Santagata, M. (2014). Pore pressure generation in sand with bentonite: From small strains to liquefaction. Géotechnique, 64(2), 108. doi:10.1680/geot.12.P.169

Nemat-Nasser, S., \& Shokooh, A. (1979). A unified approach to densification and liquefaction of cohesionless sand in cyclic shearing. Canadian Geotechnical Journal, 16(4), 659-678. doi:10.1139/t79-076

Polito, C. P., Green, R. A., \& Lee, J. (2008). Pore pressure generation models for sands and silty soils subjected to cyclic loading. Journal of Geotechnical and Geoenvironmental Engineering, 134(10), 1490-1500. doi:10.1061/ (ASCE) 1090-0241(2008)134:10(1490)

Porcino, D., Caridi, G., \& Ghionna, V. N. (2008). Undrained monotonic and cyclic simple shear behaviour of carbonate sand. Géotechnique, 58(8), 635-644. doi:10.1680/geot.2007.00036

Porcino, D., Marcianò, V., \& Granata, R. (2015). Cyclic liquefaction behaviour of a moderately cemented grouted sand under repeated loading. Soil Dynamics and Earthquake Engineering, 79, 36-46. doi:10.1016/ j.soildyn.2015.08.006

Poulos, H. G. (1988). Cyclic stability diagram for axially loaded piles. Journal of Geotechnical Engineering, 114(8), 877-895. doi:10.1061/(ASCE)0733-9410(1988)114:8(877)

Pra-Ai, S. (2013). Behaviour of soil-structure interfaces subjected to a large number of cycles. (Application to piles. Ph. D. thesis). Université de Grenoble, France.

Pra-Ai, S., \& Boulon, M. (2017). Soil-structure cyclic direct shear tests: A new interpretation of the direct shear experiment and its application to a series of cyclic tests. Acta Geotechnica, 12, 107-127. doi:10.1007/s11440-0160456-6

Qian, J. G., Du, Z. B., \& Yin, Z. Y. (2018). Cyclic degradation and non-coaxiality of soft clay subjected to pure rotation of principal stress directions. Acta Geotech, 13(4), 943-959. doi:10.1007/s11440-017-0567-8

Qian, J. G., Wang, Y. G., Yin, Z. Y., \& Huang, M. S. (2016). Experimental identification of plastic shakedown behavior of saturated clay subjected to traffic loading with principal stress rotation. Engineering Geology, 214, 29-42. doi: 10.1016/j.enggeo.2016.09.012

Seed, H. B., \& Idriss, I. M. (1971). Simplified procedure for evaluating soil liquefaction potential. Journal of Soil Mechanics \& Foundations Division, 91(9), 1249-1274.

Sherif, M. A., Ishibashi, I., \& Tsuchiya, C. (1978). Pore-pressure prediction during earthquake loadings. Soils and Foundations, 18(4), 19-30. doi:10.3208/sandf1972.18.4_19

Sivathayalan, S. (1994). Static, cyclic and post liquefaction simple shear response of sands. Canada: University of British Columbia.

Towhata, I., \& Ishihara, K. (1985). Shear work and pore water pressure in undrained shear. Soils and Foundations, 25(3), 73-84. doi:10.3208/sandf1972.25.3_73

Tsuha, C. H. C., Foray, P., Jardine, R., Yang, Z., Silva, M., \& Rimoy, S. (2012). Behaviour of displacement piles in sand under cyclic axial loading. Soils and Foundations, 52(3), 393-410. doi:10.1016/j.sandf.2012.05.002

Vaid, Y. P., \& Chern, J. C. (1983). Effect of static shear on resistance to liquefaction. Soils and Foundations, 23(1), 47-60. doi:10.3208/sandf1972.23.47

Vaid, Y. P., \& Negussey, D. (1984). Relative density of pluviated sand samples. Soils and Foundations, 24(2), $101-105$. doi:10.3208/sandf1972.24.2_101

Vaid, Y. P., Stedman, J., \& Sivathayalan, S. (2001). Confining stress and static shear effects in cyclic liquefaction. Canadian Geotechnical Journal, 38(3), 580-591. doi:10.1139/t00-120

Wang, J., Cai, Y. Q., \& Yang, F. (2013). Effects of initial shear stress on cyclic behavior of saturated soft clay. Marine Georesources \& Geotechnology, 31(1), 86-106. doi:10.1080/1064119X.2012.676153 
Wang, J., Guo, L., Cai, Y. Q., Xu, C. J., \& Gu, C. (2013) Strain and pore pressure development on soft marine clay in triaxial tests with a large number of cycles. Ocean Engineering, 74, 125-132. doi:10.1016/j.oceaneng.2013.10.005

Wang, J., Liu, F. Y., Wang, P., \& Cai, Y. Q. (2016). Particle size effects on coarse soil-geogrid interface response in cyclic and post-cyclic direct shear tests. Geotextiles and Geomembranes, 44(6), 854-861. doi:10.1016/ j.geotexmem.2016.06.011

Wichtmann, T., \& Triantafyllidis, T. (2016a). An experimental data base for the development, calibration and verification of constitutive models for sand with focus to cyclic loading: Part I-tests with monotonic loading and stress cycles. Acta Geotechnica, 11(4), 739-761. doi:10.1007/s11440-015-0402-z

Wichtmann, T., \& Triantafyllidis, T. (2016b). An experimental data base for the development, calibration and verification of constitutive models for sand with focus to cyclic loading: Part II - tests with strain cycles and combined loading. Acta Geotechnica, 11(4), 763-774. doi:10.1007/s11440-015-0412-x

Yang, J., \& Sze, H. (2011). Cyclic behaviour and resistance of saturated sand under non-symmetrical loading conditions. Géotechnique, 61(1), 59-73. doi:10.1680/geot.9.P.019

Yang, Z., Jardine, R., Zhu, B., Foray, P., \& Tsuha, C. (2010). Sand grain crushing and interface shearing during displacement pile installation in sand. Géotechnique, 60(6), 469-482. doi:10.1680/geot.2010.60.6.469

Yang, Z., \& Pan, K. (2017). Flow deformation and cyclic resistance of saturated loose sand considering initial static shear effect. Soil Dynamics and Earthquake Engineering, 92(2017), 68-78. doi:10.1016/j.soildyn.2016.09.002

Yin, Z. Y., Chang, C. S., \& Hicher, P. Y. (2010). Micromechanical modelling for effect of inherent anisotropy on cyclic behaviour of sand. International Journal of Solids and Structures, 47(14-15), 1933-1951. doi:10.1016/ j.ijsolstr.2010.03.028

Yin, Z. Y., Wu, Z. Y., \& Hicher, P. Y. (2018). Modeling the monotonic and cyclic behavior of granular materials by an exponential constitutive function. Journal of Engineering Mechanics ASCE, 144(4), 04018014. doi:10.1061/ (ASCE)EM.1943-7889.0001437

Yin, Z. Y., Xu, Q., \& Chang, C. S. (2013). Modeling cyclic behavior of clay by micromechanical approach. ASCE Journal of Engineering Mechanics, 139(9), 1305-1309. doi:10.1061/(ASCE)EM.1943-7889.0000516

Yoshimine, M., Ishihara, K., \& Vargas, W. (1998). Effects of principal stress direction and intermediate principal stress on undrained shear behavior of sand. Soils and Foundations, 38(3), 179-188. doi:10.3208/sandf.38.3_179

Yoshimine, M., Robertson, P., \& Wride, C. (1999). Undrained shear strength of clean sands to trigger flow liquefaction. Canadian Geotechnical Journal, 36(5), 891-906. doi:10.1139/t99-047 